\title{
Sonochemical Synthesis of Nano-Structured Hydroxyapatite with unique morphologies and Evaluation of Sintering Kinetics
}

\section{Papiya Biswas, Bandhakavi Lakshmi Sindhura, Chandhana Muraleedharan Nair, Pandu}

Ramavath, Madireddy Buchi Suresh and Roy Johnson*

International Advanced Research Centre for Powder Metallurgy and New materials (ARCI), Hyderabad- 500

005, India

papiya@arci.res.in

International Advanced Research Centre for Powder Metallurgy and New materials (ARCI), Hyderabad- 500 005, India

royjohnson@arci.res.in

International Advanced Research Centre for Powder Metallurgy and New materials (ARCI), Hyderabad- 500 005, India

suresh@arci.res.in

\begin{abstract}
Phase pure hydroxyapatite $(\mathrm{HAp})\left(\mathrm{Ca}_{10}\left(\mathrm{PO}_{4}\right)_{6}(\mathrm{OH})_{2}\right)$ ceramic powder was synthesized from the stoichiometric solution of calcium hydroxide and orthophosphoric acid employing sonochemical technique. Crystallinity of the HAp powder is found to be a strong function of amplitude of the ultrasound generator as revealed by XRD patterns and FTIR recorded on the samples prepared using varying amplitudes. Calcination of $\mathrm{HAp}$ powder beyond $700^{\circ} \mathrm{C}$ has resulted in the initiation of sintering as is evident from dilatometric studies and are complimented by the SEM micrographs. Activation energy of sintering of hydroxyapatite pellets using dilatometric sintering kinetic analysis has estimated to be $668 \pm 45 \mathrm{~kJ} / \mathrm{mole}$ corresponding to grain boundary diffusion as the prominent mass transport mechanism. Samples exhibited a density of $3.12 \mathrm{~g} / \mathrm{cm}^{3}$, close to theoretical density $(\sim 99 \%)$ at the peak temperature of $1200^{\circ} \mathrm{C}$. Studies on AC conductivity of the sintered samples exhibited relatively high room temperature conductivity of $5.07 \times 10^{-8} \mathrm{~S} / \mathrm{m}$ and a rising trend with temperature probably due to mobility of $\mathrm{H}^{+}$and $\mathrm{OH}^{-}$ions. Attempts were also made to produce HAp nanorods sonochemically on the ordinary glass substrates immersed in the stoichiometric HAp precursor solution. Surface topographic images of the HAp deposited on glass substrate exhibited nanorods almost individually separated with an average diameter of $50 \mathrm{~nm}$ and $200 \mathrm{~nm}$ in length providing a process for synthesizing nano-structured HAp with simultaneous deposition exhibiting unique morphologies.
\end{abstract}

Keywords: Hydroxyapatite; Nanorods; Sonochemical synthesis; X-ray diffraction; Activation energy

*Author for correspondence: Tel: 00914024443169, Fax: 00914024442699, E-mail: royjonson@arci.res.in

\section{Council for Innovative Research}

Peer Review Research Publishing System

\section{Journal: Journal of Advances in Chemistry}

Vol. 11, No. 8

editorjaconline@gmail.com, www.cirjac.com 


\section{INTRODUCTION}

Hydroxyapatite $\left(\mathrm{Ca}_{10}\left(\mathrm{PO}_{4}\right)_{6}(\mathrm{OH})_{2}\right),(\mathrm{HAp})$ is recognized as a substitute in the field of orthopedic and dentistry because of its inherent resemblance in chemistry to the mineral constituents of the human calcified tissues [1-3]. HAp in addition to the advantages of biocompatibility and bioactivity, it is possible to engineer the surface morphology and porosity to enhance the resorbability, osteoconductivity and also binding affinity to variety of pharmacological substances [4-5]. This has recently opened up a vide scope to deliver pharmacological substances in many clinical applications. Synthetic methodologies are reported to have a prominent effect on the properties of HAp. Generally HAp is synthesized by various methodologies such as precipitation, sol-gel, hydrothermal as well as biomimetic and electrodeposition techniques etc [6-9]. Chemical precipitation techniques generally employ stoichiometric chemical reaction. However, temperature, $\mathrm{pH}$, acid addition rate and suspension dispersion etc. are reported to be very sensitive to the powder properties such as size, shape and surface area which controls the clinical applications. Hydrothermal synthesis uses heterogeneous/homogeneous phase reaction at elevated temperature $\left(\mathrm{T}>25^{\circ} \mathrm{C}\right)$ and pressure $(\mathrm{P}>100 \mathrm{kPa})$ to crystallize HAp directly from solutions. However, sonochemical synthesis of HAp formulation though reported [10-11] has not been explored fully with various sonic and processing parameters.

In the present study, a stoichiometric precursor solution corresponding to HAp was prepared from calcium hydroxide and orthophosphoric acid. The resultant solution was irradiated with the ultrasonic waves to sonochemically precipitate the bioactive hydroxyapatite formulation. Effect of amplitude of the ultrasound generator and the viscosity of reaction medium leading to acoustic impedance were evaluated. Further, the effect on treatment conditions such as temperature and duration of stirring of the reaction medium were also studied. The present study revealed a sonic amplitude of $50 \%$ for a period of 1 hour under constant magnetic stirring was found to be optimum for the evaluation of crystalline HAp phase. The temperature generated was around $50^{\circ} \mathrm{C}$ during the experiments. Sonochemically synthesized powder was compacted into pellets and subjected to dilatometric sintering studies and achieved close to theoretical density. The activation energy of the sintering is estimated to be $668 \pm 45 \mathrm{~kJ} / \mathrm{mole}$ proposing grain boundary diffusion as the prominent mass transport mechanism while sintering. The sintered samples were further subjected to AC conductivity studies and post sinter hot isostatic pressing. Additionally, it was also observed that HAp nanorods can be simultaneously synthesized and deposited sonochemically on a glass plate immersed in the stiochiometric precursor solution.

\section{EXPERIMENTAL}

\subsection{SONOCHEMICAL SYNTHESIS OF HYDROXYAPATITE}

Analytical grade calcium hydroxide $\left(\mathrm{Ca}(\mathrm{OH})_{2}\right.$ and orthophosphoric acid $\left(\mathrm{H}_{3} \mathrm{PO}_{4}\right)$ were dissolved in water in stoichiometric proportion as per the equation 1. Stoichiometric solution was irradiated using an ultrasonicator with a probe and the experimental set up is depicted in Fig 1. The set up consist of an ultrasonic processor with a probe of diameter 20 $\mathrm{mm}$ and the variation in the power can be achieved by varying the amplitude at different levels from 25 to $50 \%$. Further, in order to evaluate the power dissipation at different amplitude levels, $100 \mathrm{ml}$ of stoichiometric solution, kept in the beaker under continuous stirring and was irradiated with ultrasonic waves. Temperature was also measured with a thermocouple placed close to the ultrasonic probe. Precipitate formed with varying the amplitude at different percentage levels were collected and characterized for various powder properties.

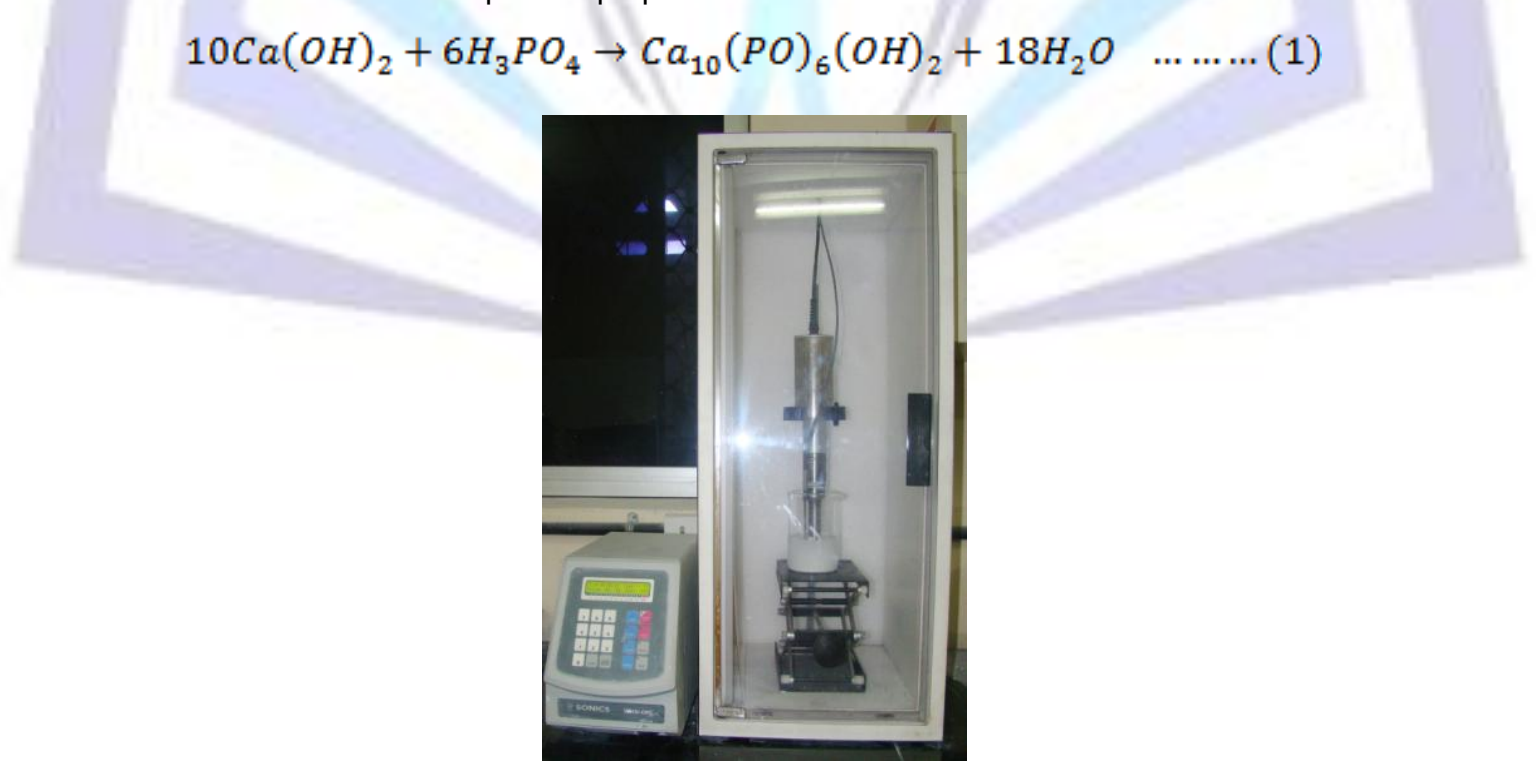

Fig 1: Photograph of ultrasonicator 
Phase analyses were done by X-ray diffraction (XRD) using D8 advanced system, equipped with LynxEye ${ }^{\mathrm{TM}}$ (Bruker, Karlsruhe, Germany). Crystalline phase was identified based on the comparison of the observed d-spacing and relative intensities with those of a reference material pattern compiled in the ICDD database and the crystallite size was estimated using sherrer's equation. Functional group identification was carried out using FTIR spectroscopy (Spectrum GX, Perkin Elmer, Singapore). As the evolution of hydroxyapatite phase is more prominent with $50 \%$ amplitude this powder selected for further studies. In order to study the crystallinity of the powder as a function of calcination temperature the powder was calcined at $600^{\circ} \mathrm{C}$ and $700^{\circ} \mathrm{C}$ for $2 \mathrm{hrs}$. Further, morphology of hydroxyapatite powder was assessed with scanning electron microscopy (SEM) (Hitachi 3200S, FE SEM, Japan) before and after calcination. Particle size was determined using photon correlation spectroscopy (DLS) (Nanosizer, Malvern, UK) employing the aqueous slurry dispersed with Darvan 821A (ammonium polyacrylate; RT Vanderbilt Inc, CT, USA). HAp powder was compacted into a $10 \mathrm{~mm}$ diameter and $5 \mathrm{~mm}$ height pellets for dilatometric sintering studies. Impedance measurements were carried out using an impedance analyzer (Solartron SI1260, Ametek, Inc., Hampshire, UK) in the frequency range varying from $0.1 \mathrm{~Hz}$ to $10 \mathrm{MHz}$ with $\mathrm{AC}$ amplitude of $100 \mathrm{mV}$. Prior to the measurement, sample is coated with platinum on both the surfaces and cured at $800^{\circ} \mathrm{C}$ for $30 \mathrm{~min}$. The platinum coated HAp sample is placed in a sample holder and impedance is carried out between $30^{\circ} \mathrm{C}-650^{\circ} \mathrm{C}$ at $50^{\circ} \mathrm{C}$ increment. Additionally attempts were also made to explore the possibility of simultaneous synthesis and deposition of HAp nanorods sonochemically on glass substrates of dimensions 100 (L) $\times 25$ (B) $\times 3 \mathrm{~mm}(\mathrm{H})$. The glass substrates were immersed in the HAp stoichimetric solution and were irradiated with ultrasonic waves of $50 \%$ amplitude. Surface topography of the HAp deposited glass substrates were examined using FESEM (Hitachi 3200 S, Tokyo, Japan).

\section{RESULTS AND DISCUSSION}

The XRD patterns of as-synthesized powder under different amplitudes are shown in Fig 2. XRD peaks at $2 \theta$ values 31.94, 32.85 and 34.11 (JCPDS files (74-0565)) from planes of (211), (300) and (202) confirmed the formation of HAp and the crystallite size was found to be around $8 \mathrm{~nm}$. It is known that change of amplitude of ultrasonic waves is a function of ultrasound intensity. In the present study, it is observed that out of the various amplitudes of 25 to $50 \%$ employed, amplitude of $50 \%$ is found to be optimum. This experimental condition has generated the maximum ultrasound intensity corresponding to a maximum temperature of $50^{\circ} \mathrm{C}$ recorded during the experiments. This is also evident from the more crystallinity of the powder observed under this condition (Fig 2). Efficiency of the ultrasound for chemical synthesis is not only depends on ultrasonic generator performance parameters (frequency, power input etc.) but also on the physicochemical properties of reaction medium (Gibbs free energy of the reaction, viscocity, surface tension and acoustic impedance). Further, the efficiency also depends on the treatment conditions such as temperature and stirring of the reaction medium etc. As the ultrasonic irradiation wave cause the molecules of the solution to oscillate about the mean position during cyclic compression and refraction the distance between the molecules decreases and increases respectively. This creates innumerable shock waves in the stoichiometric solution and the cumulative effect causes high energy levels generated within the liquid which in turn responsible for the chemical reaction as depicted in equation (1) to occur. The solution temperature also raised to $50^{\circ} \mathrm{C}$ as a result of excess energy dissipation.

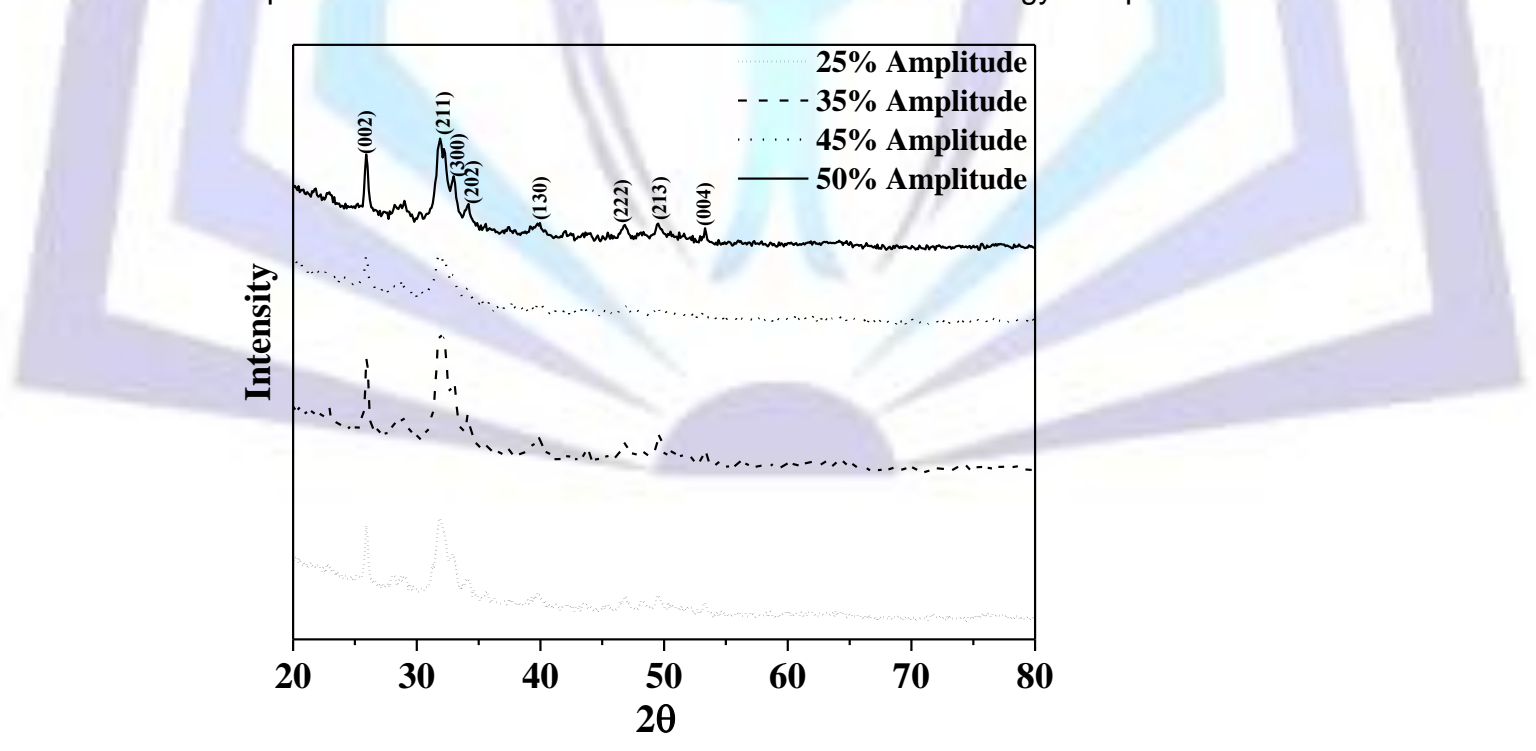

Fig 2: XRD pattern of HAp synthesized in the amplitude range of $25-50 \%$ 


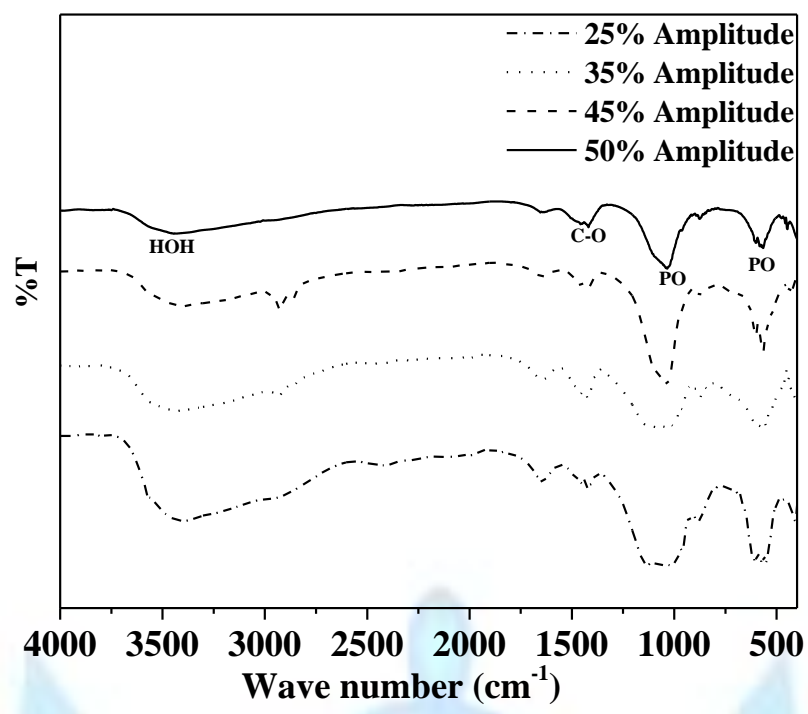

Fig 3: FTIR spectra of HAp synthesized in the amplitude range of $25-50 \%$

FTIR spectra of HAp powders synthesized under varying amplitudes are shown in Fig 3. IR spectra exhibited absorption band at $3571 \mathrm{~cm}^{-1}$ arising due to hydroxyl group stretching mode. Peaks at 1067,978 and $588 \mathrm{~cm}^{-1}$ can be attributed to bending mode of $\mathrm{PO}_{4}$ functional group and further an absorption band corresponding to $\mathrm{C}-\mathrm{O}\left(1440 \mathrm{~cm}^{-1}\right)$ stretch is also seen from the spectra which can be due to the adsorption of atmospheric $\mathrm{CO}_{2}$ by the HAp sample. Fig 4 and Fig 5 shows the XRD patterns and FTIR spectra of hydroxyapatite powder calcined at $600^{\circ} \mathrm{C} / 2 \mathrm{~h}$ (b) and $700^{\circ} \mathrm{C} / 2 \mathrm{~h}$ (c) along with the as synthesized powder under the amplitude of $50 \%$ (a) respectively for better comparison. It is evident that calcinations at $600^{\circ} \mathrm{C} / 2 \mathrm{~h}$ and $700^{\circ} \mathrm{C} / 2 \mathrm{~h}$ resulted in better crystallinity and also well defined and prominent finger prints in FTIR spectra. An average particle size of $282 \mathrm{~nm}$ is observed for as synthesized powder and further calcination at $600^{\circ} \mathrm{C}$ and $700^{\circ} \mathrm{C}$ do not exhibited any substantial increase in the particle size. However, it is not appropriate to calcine beyond $700^{\circ} \mathrm{C}$ as the sintering process is initiated around $700-800^{\circ} \mathrm{C}$ as revealed by SEM images shown in Fig $6(\mathrm{a}-\mathrm{C})$ which is further complemented by the sintering curves depicted in Fig 7 .

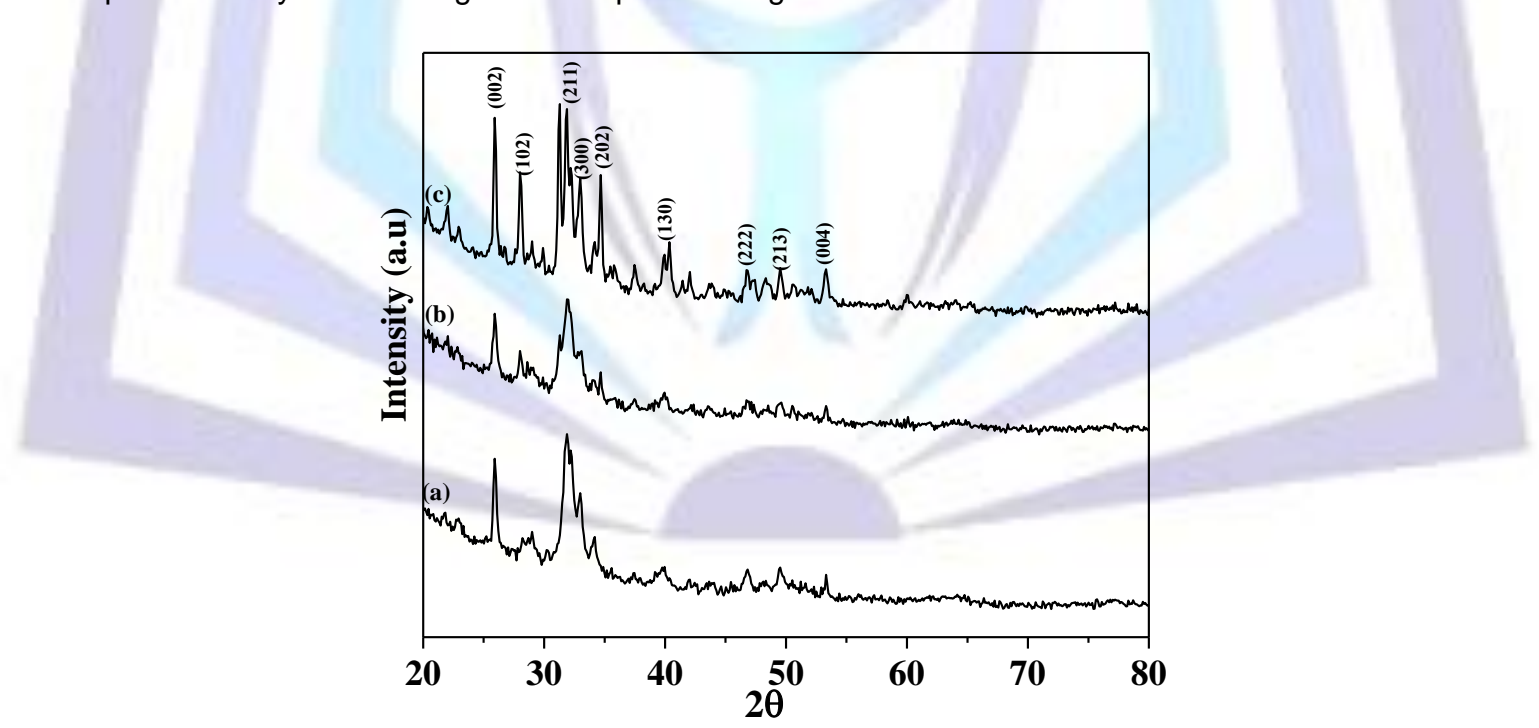

Fig 4: XRD Patterns of (a) hydroxyapatite synthesized under $50 \%$ amplitude (b) hydroxyapatite calcined at $600^{\circ} \mathrm{C} / 2 \mathrm{~h}(\mathrm{c})$ hydroxyapatite calcined at $700^{\circ} \mathrm{C} / 2 \mathrm{~h}$ 


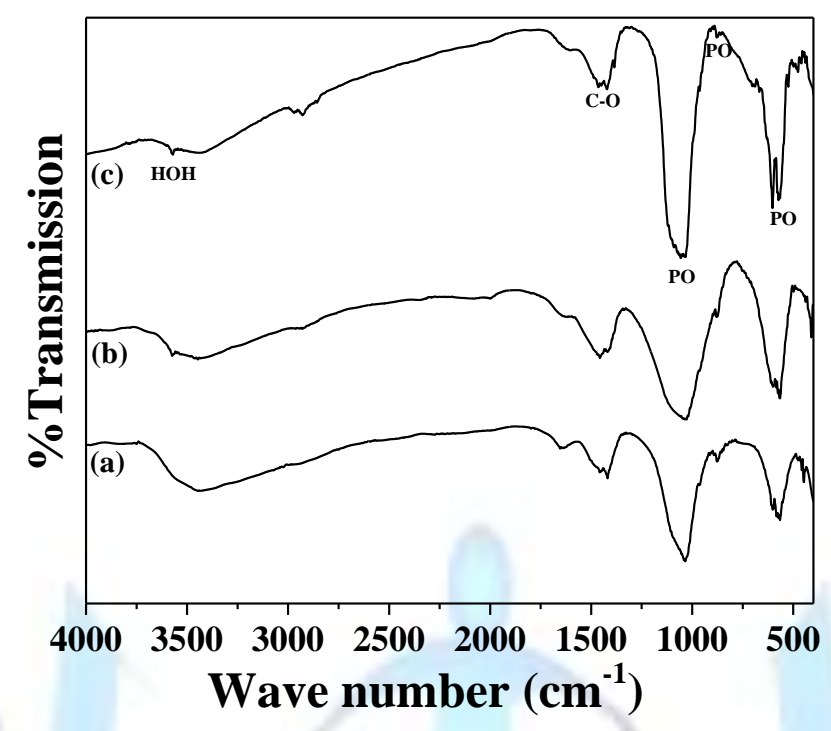

Fig 5: FTIR Spectra of (a) hydroxyapatite synthesized under 50\% amplitude (b) hydroxyapatite calcined at $600^{\circ} \mathrm{C} / 2 \mathrm{~h}$ (c) hydroxyapatite calcined at $700^{\circ} \mathrm{C} / 2 \mathrm{~h}$
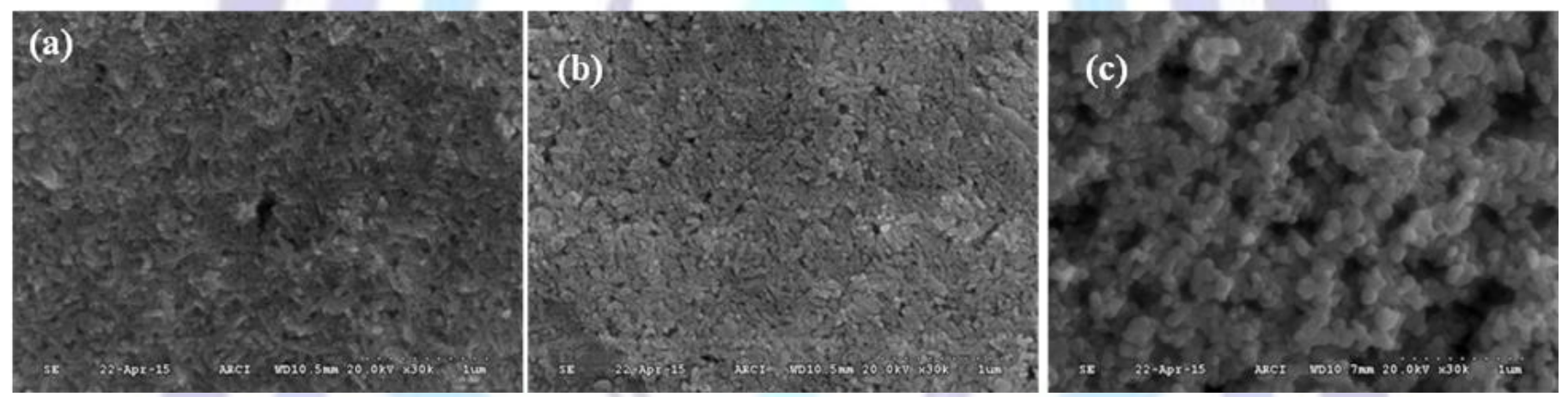

Fig 6: (a) SEM image of (a) as sonochemically synthesized hydroxyapatite (b) hydroxyapatite calcined at $600^{\circ} \mathrm{C} / 2 \mathrm{~h}$ and (c) calcined hydroxyapatite at $700^{\circ} \mathrm{C} / 2 \mathrm{~h}$

\subsection{SINTERING STUDIES ON HYDROXYAPATITE CERAMICS}

Fig 7 shows the dilatometric shrinkage curve at three different heating rate of 5,10 and $20^{\circ} \mathrm{C} / \mathrm{min}$ and further the relative density with respect to temperature at different heating rate are shown in Fig 8 . It is evident that, HAp pellets exhibited almost negligible shrinkage till $800^{\circ} \mathrm{C}$ and final shrinkage in case of $10^{\circ} \mathrm{C} / \mathrm{min}$ which supersedes the heating rate of 5 and $20^{\circ} \mathrm{C} / \mathrm{min}$. Initiation of shrinkage starts at around $530^{\circ} \mathrm{C}$ with a shrinkage rate of $2.67 \mu \mathrm{m} / \mathrm{min}$ up to a temperature of $680^{\circ} \mathrm{C}$ corresponding to a densification of $75 \%$ of the theoretical. A shrinkage rate of $11.33 \mu \mathrm{m} / \mathrm{min}$ up to a temperature of $900^{\circ} \mathrm{C}$ corresponding to a densification of $85 \%$ of the theoretical. Shrinkage rate becomes prominent (19um/min) upto a temperature of $1200^{\circ} \mathrm{C}$ corresponding to faster densification. Beyond $1200^{\circ} \mathrm{C}$ the density becomes close to theoretical as revealed by the shrinkage curve tapering close to a platue. 


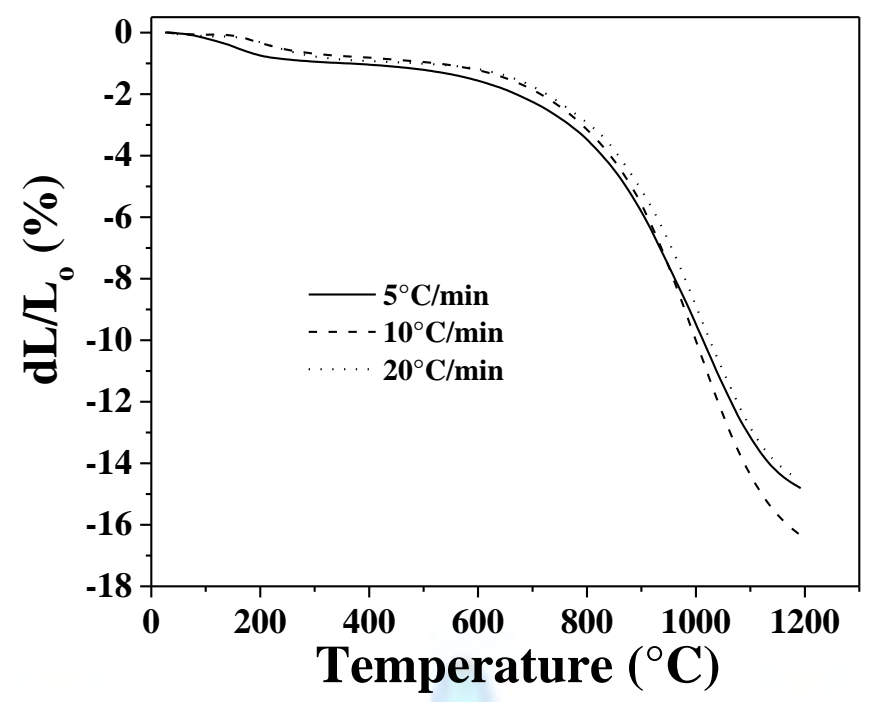

Fig 7: Dilatometric shrinkage curves at 5,10 and $20^{\circ} \mathrm{C} / \mathrm{min}$ heating rate

Sintering involves various mechanisms which controls the densification throughout the process. Prediction of the sintering behavior is rather cumbersome even though the thermal history of the sample is known [12] hence theoretical models have been in extensive use to describe the sintering kinetics of ceramic systems [13]. Estimation of activation energy of sintering using method of Wang and Raj [14] was found to be relatively simple and reliable to predict the finaldensities.

Based on the $\mathrm{dL} / \mathrm{L}_{0}$ (change in length to original length) values obtained from dilatometric curve the instantaneous relative density $(\rho)$ can be calculated using equation (2), where $\rho_{0}$ is the green density

$\rho=\frac{\rho_{0}}{\left(1-\frac{d l}{l_{0}}\right)^{3}} \times 100$

Substituting the absolute value of shrinkage $\mathrm{dL} / \mathrm{L}_{0}$ in the equation (2) for the three different heating rates the relative densities are estimated and the plot showing relative density versus temperature is depicted in Fig. 8 .

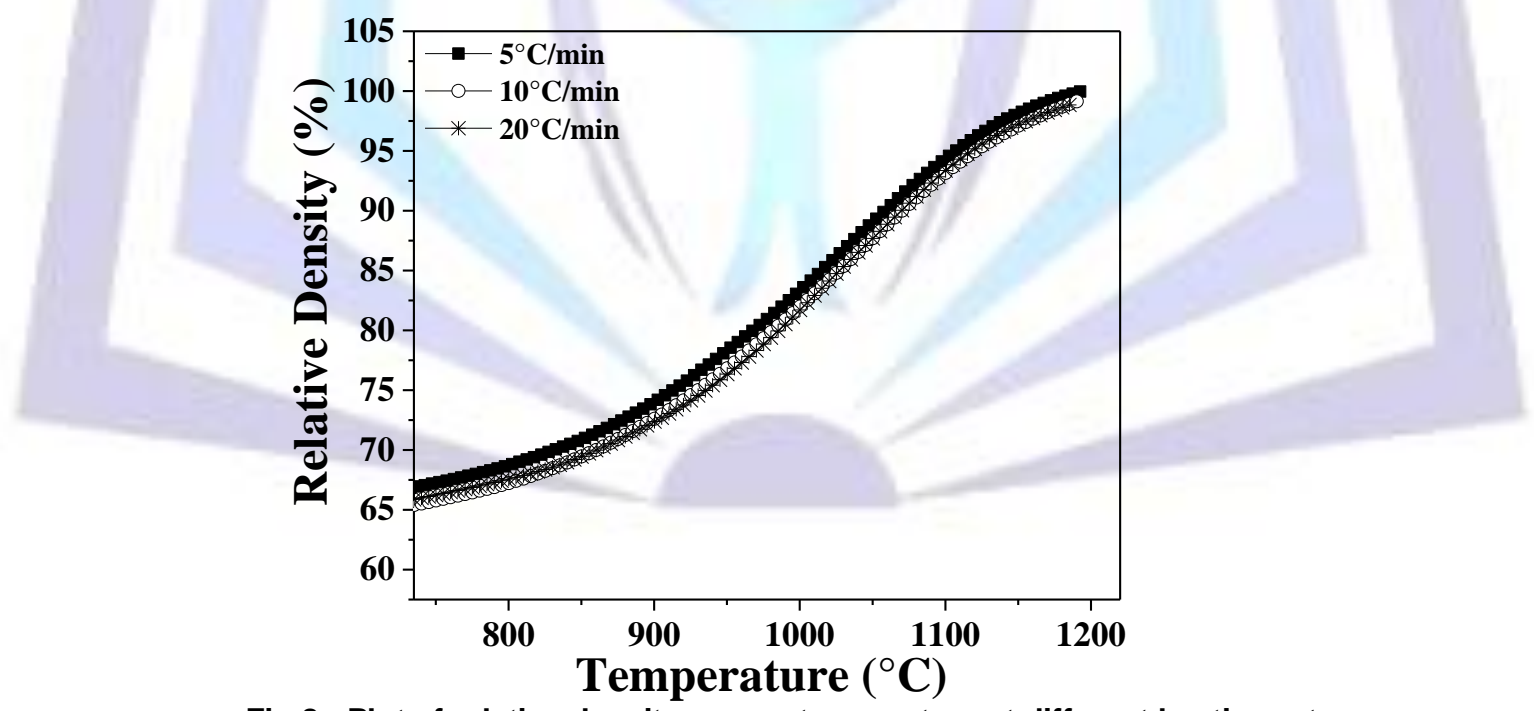

Fig 8: Plot of relative density versus temperature at different heating rate

Sintering rate equation can be written as,

$\dot{\rho}=A \frac{e^{-Q / R T}}{T} \frac{f(\rho)}{d^{n}}$

Where $\dot{\rho}$ - is the instantaneous relative density of the sample, R- is the universal constant, $\mathrm{Q}$ - activation energy, A- pre-exponential factor, $\mathrm{T}$ - temperature, $\mathrm{d}$ - the grain size and $\mathrm{n}$ - the grain size exponent. Applying Log to the above equation and can be written as 
$\ln \left(T \dot{T} \frac{d \rho}{d T}\right)=-\frac{Q}{R T}+\ln [f(\rho)]+\ln A-n \ln d$

Hence the plot (shown in Fig 9) of left hand side versus 1/T will be straight line and the slope of the straight line will be estimated as the activation energy Q. Activation energy of the sintering is estimated to be $668 \pm 45 \mathrm{~kJ} / \mathrm{mole}$. Activation energy of $668 \pm 45 \mathrm{~kJ} /$ mole corresponds to the grain boundary diffusion which is the mass transport mechanism. The HAp specimen sintered at $1200^{\circ} \mathrm{C}$ with a heating rate of $10^{\circ} \mathrm{C} / \mathrm{min}$ have shown a density of $3.12 \mathrm{~g} / \mathrm{cc}$ which corresponds to a $99 \%$ of the theoretical density.

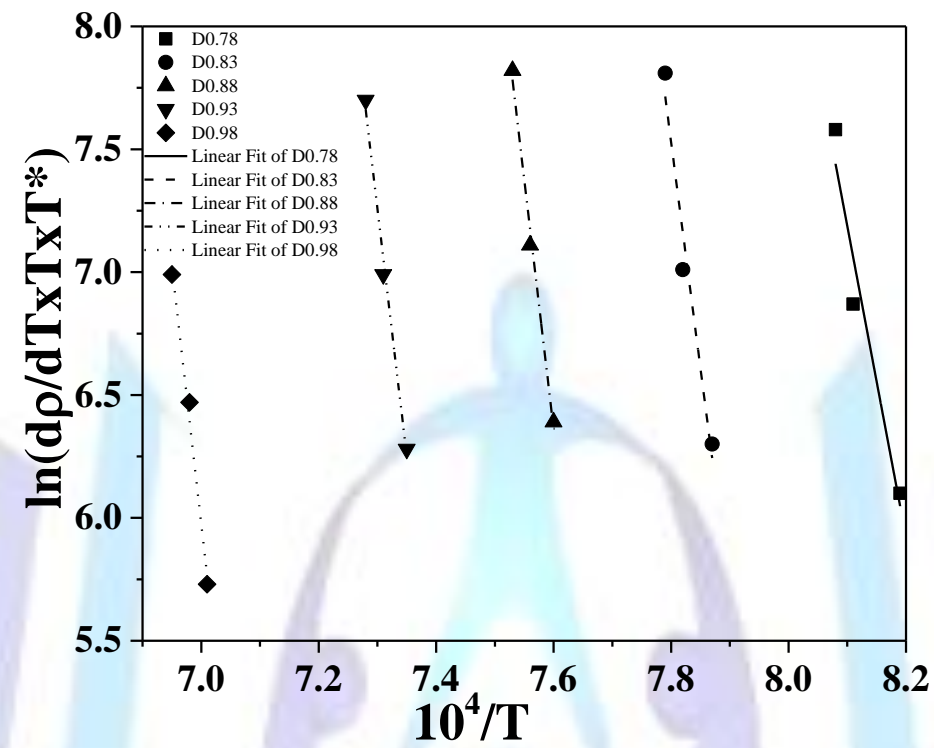

Fig 9: Arrhenius plot and estimation of activation energy

\subsection{IMPEDANCE MEASUREMENTS}

Fig 10 shows the variation of $\mathrm{AC}$ conductivity $\left(\sigma_{\mathrm{AC}}\right)$ with temperature of sintered HAp sample. The $A C$ conductivity pattern indicates a progressive rise in conductivity with increasing temperature in the low temperature regimes with a more prominent enhancement in conductivity at higher temperatures. The AC conductivity estimated in the present study at RT is $5.07 \times 10^{-8} \mathrm{~S} / \mathrm{m}$, and is found to be two orders higher than the reported value of AC conductivity at RT by Nagai and Nishino $\left(6.6 \times 10^{-10} \mathrm{~S} / \mathrm{m}\right)[15]$. The activation energy (Ea) has been calculated from the slope of a straight line in the low and high temperature regimes. Further, a low activation energy of $0.07 \mathrm{eV}$ was calculated from the AC conductivity which can be correlated with the existence of space charges and $\mathrm{H}^{+}$ion conduction. Activation energy of $1.08 \mathrm{eV}$ observed in the high temperature regimes can be attributed to the mobility of $\mathrm{OH}^{-}$ions which complements with earlier reports of activation energy in the range of $0.7-1.4 \mathrm{eV}$ for $\mathrm{OH}^{-}$ions [16-18].

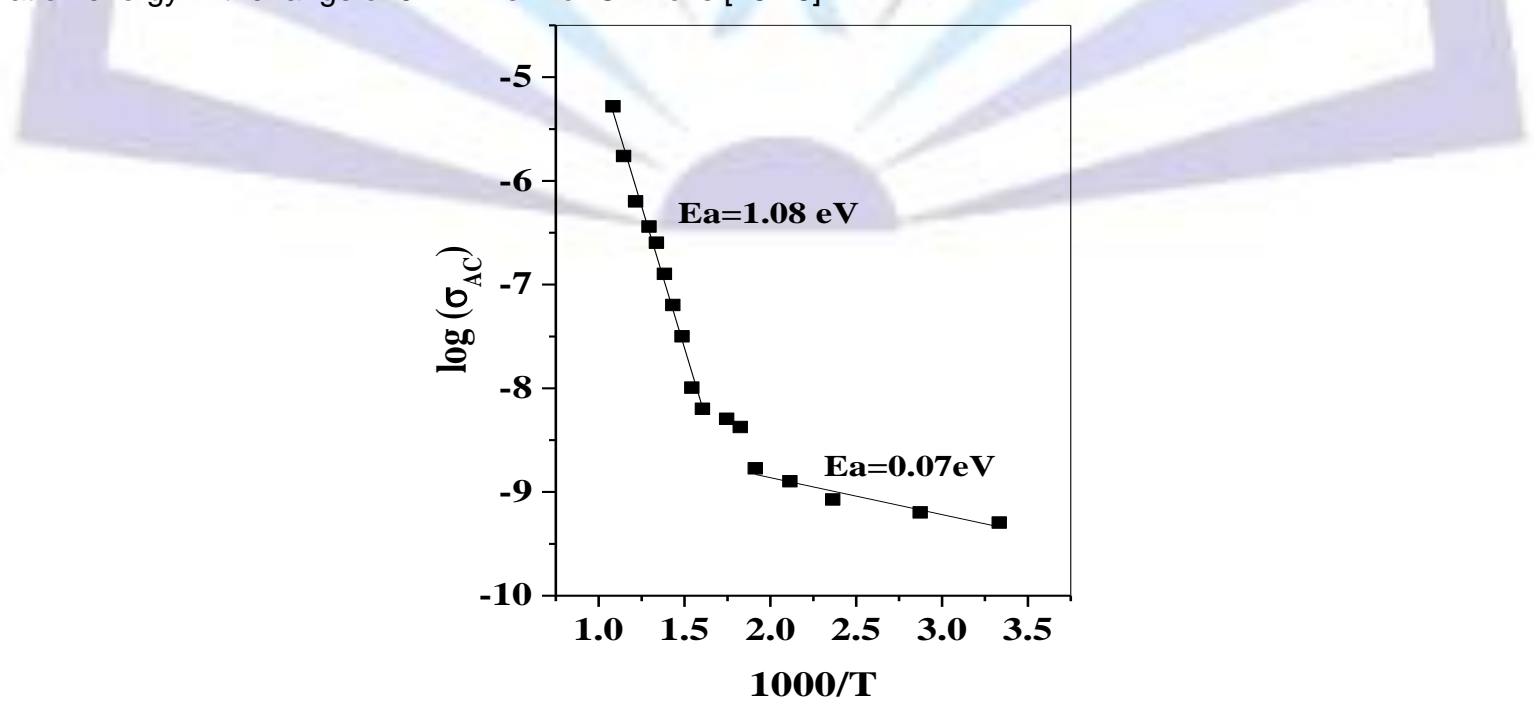

Fig 10: Plot of $\sigma_{\mathrm{AC}}$ versus 1/T 
Fig 11 shows the surface topographic images of the HAp nanorods synthesized and simultaneously deposited from the stoichiometric solution on the surface of the glass plate as a result of the sonochemical irradiation. Though, several images are recorded from the samples collected from different parts, for the sake of clarity only representative SEM image is shown in the manuscript. It is evident from SEM images that the HAp appears as nanorods almost individually separated with an average diameter of $50 \mathrm{~nm}$ and $200 \mathrm{~nm}$ length and the chemical composition was confirmed by the EDS analysis as HAp stoichiometry. Thus, the present study demonstrated a new and unique sonochemical process for the synthesis and simultaneous deposition of HAp nanorods on the glass substrates.

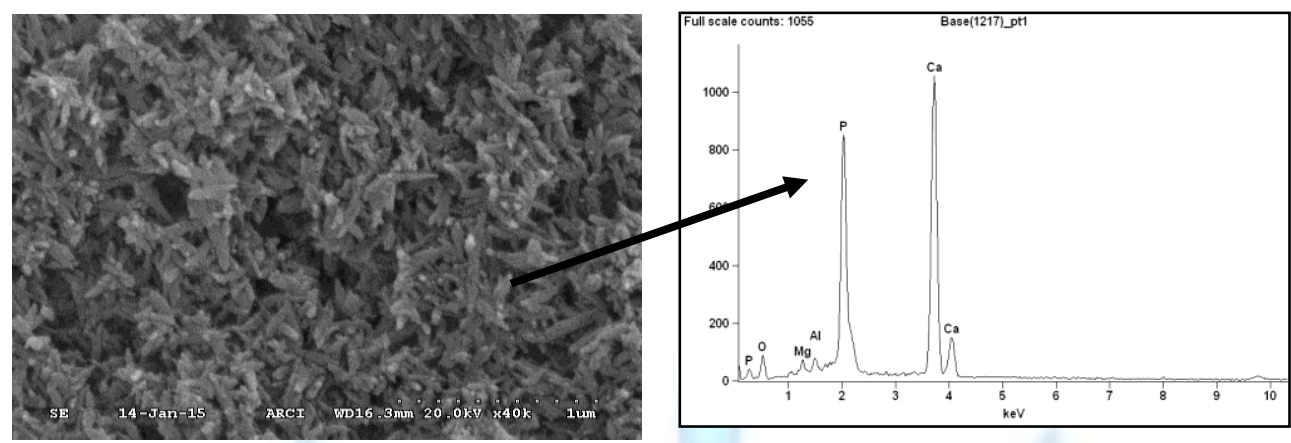

Fig 11: Surface Topography of HAp deposited on glass substrates along with EDS analysis

\section{CONCLUSIONS}

Phase pure hydroxyapatite $\left(\mathrm{Ca}_{10}\left(\mathrm{PO}_{4}\right)_{6}(\mathrm{OH})_{2}\right)$ ceramic powders were synthesized from the stoichiometric solution of calcium hydroxide and orthophosphoric acid with the ultrasonic waves through sonochemical synthesis. Amplitude of the ultrasound generator as well as the viscosity of reaction medium and resulting acoustic impedance is found to have an influence on the crystallinity of the HAp composition. Out of sonic amplitudes from 25 to $50 \%$, amplitude of $50 \%$ for a period of 1 hour under constant magnetic stirring yielded the maximum crystallinity as revealed by the XRD results. Calcination of HAp powder has resulted in more crystallinity and no substantial change in the particle size was observed. A calcination temperature beyond $700^{\circ} \mathrm{C}$ is not appropriate as complemented by dilatometric sintering curves and the SEM micrographs. HAp pellets sintered at $1200^{\circ} \mathrm{C}$ with a heating rate of $10^{\circ} \mathrm{C} / \mathrm{min}$ have shown a density of 3.12 $\mathrm{g} / \mathrm{cm}^{3}$ which corresponds to a $99 \%$ of the theoretical density. Activation energy of the sintering of HAp pellets is estimated to be $668 \pm 45 \mathrm{~kJ} / \mathrm{mole}$ based on dilatometric sintering kinetic studies. The activation energy of $668 \pm 45 \mathrm{~kJ} / \mathrm{mole}$ proposes grain boundary diffusion as the prominent mass transport mechanism while sintering of HAp pellets. Post sinter HIPing resulted in the translucent samples with density close to theoretical. AC conductivity measurements revealed relatively high room temperature conductivity of $5.07 \times 10^{-8} \mathrm{~S} / \mathrm{m}$ which progressively increased with temperature as a result of mobility of $\mathrm{H}^{+}$and $\mathrm{OH}^{-}$ions as correlated with corresponding activation energies. Study demonstrated a unique process of sonochemical synthesis and simultaneous deposition of HAp nanorods on the glass substrates. Surface topographic investigations of thus produced HAp nanorods are found to be almost individually separated with an average diameter of $50 \mathrm{~nm}$ and $200 \mathrm{~nm}$ length.

\section{REFERENCES}

[1] Moshaverinia, A., Ansari, S., Moshaverinia, M., Roohpour, N., Darr, J. A., Rehman, I. 2008. Effects of incorporation of hydroxyapatite and fluoroapatite nanobioceramics into conventional glass ionomer cements (GIC). Acta Biomaterialia 4, 432-440.

[2] Gibson, I. R. 2015 Synthetic hydroxyapatite for bone-healing applications, Hydroxyapatite (Hap) for Biomedical Applications, ed. Michael Mucalo, Hamilton (A volume in Woodhead Publishing Series in Biomaterials), Ch. 12, pp.269-287.

[3] Melnikov, P., Gonçalves, R. V. 2015. Preparation and characterization of strontium hydroxyapatite Sr10(PO4)6(OH)2.10H2O suitable for orthopedic applications. Mater. Lett.150, 89-92.

[4] Vahabzadeh, S., Roy, M., Bandyopadhyay A., Bose, S. 2015. Phase stability and biological property evaluation of plasma sprayed hydroxyapatite coatings for orthopedic and dental applications. Acta Biomaterialia 17, 4755.

[5] Rau, J.V., Cacciotti, I., De Bonis, A., Fosca, M., Komlev, V.S., Latini, A., Santagata A., Teghil, R. 2014. Fedoped hydroxyapatite coatings for orthopedic and dental implant applications. Applied Surface Sci. 307, 301305.

[6] Parcharoen, Y., Kajitvichyanukul, P., Sirivisoot, S., Termsuksawad, P. 2014. Hydroxyapatite electrodeposition on anodized titanium nanotubes for orthopedic applications. Applied Surface Sci. 311, 54-61.

[7] Bakan, F., Laçin O., Sarac, H. 2013. A novel low temperature sol-gel synthesis process for thermally stable nano crystalline hydroxyapatite. Powder Technol. 233, 295-302. 
[8] Inthong, S., Tunkasirin, T., Eitssayeam, S., Pengpat K., Rujijanagul, G. 2013. Physical properties and bioactivity of nanocrystalline hydroxyapatite synthesized by co-precipitation route. Ceram. Inter. 39, S533S536.

[9] García, C., García C., Paucar, C. 201th. Controlling morphology of hydroxyapatite nanoparticles through hydrothermal microemulsion chemical synthesis. Inorg. Chem. Commun. 20, 90-92.

[10] Yoruc A B H, Ipek Y 2012 Sonochemical Synthesis of hydroxyapatite nano particles with different precursor reagents, Acta Physica polonica A. 121(1) 230-232.

[11] Barandehfard F, Keyanpour-Rad M, Hoosseinnia A 2012 Sonochemical synthesis of hydroxyapatite and flouoroapatite nanosized bioceramics, J. Ceram. Process. Res., 13(4), 437-440.

[12] Teng, M.H. 2002. A computer program of master sintering curve model to accurately predict sintering results. Western pacific earth sciences 2, 171.

[13] Chu, Y., Rahaman, M.N., De Jonghe L.C., Brook, R.J. 1991. Effect of heating rate on sintering and coarsening. J. Am. Ceram. Soc. 74, 1217.

[14] Wang J., Raj, R. 1990. Estimate of the activation energies for boundary diffusion from rate-controlled sintering of pure alumina, and alumina doped with zirconia or titania. J. Am. Ceram. Soc. 73, 1172.

[15] M. Nagai and T. Nishino, Solid State Ionics, 1988, 28-30, 1456-1461 Surface conduction of porous hydroxyapatite ceramics at elevated temperatures.

[16] K. Yamashita, K. Kitagaki and T. Umegaki, J. Am. Ceram. Soc., 1995, 78,1191-1197.

[17] T. Takahashi, S. Tanase and O. Yamamoto, Electrochim Acta, 1978, 23, 369-373 .

[18] A. Laghzizil, N. Elherch, A. Bouhaouss, G. Lorente, T. Coradin and J. Livage, Mater. Res. Bull., 2001, 36, 953962 . 